\title{
How the COVID-19 pandemic has enforced a new way of surgical training
}

\author{
Ankit Rai · Farhanul Huda · Somprakas Basu
}

Received: 3 January 2021 / Accepted: 8 April 2021 / Published online: 30 April 2021

(c) Springer-Verlag GmbH Austria, part of Springer Nature 2021

\section{Dear Editors,}

The medical profession today is facing perhaps the biggest challenge of this century. The battle against COVID-19 has affected patient care on all fronts. Since clinical training is a product of good healthcare, it has suffered the most, due to dwindling patient numbers and administrative priorities. With a vaccination program that is yet to be universal and an emerging threat of newer strains of the virus, surgical training has faced the pressure of accommodating to the new normal during the present crisis [1].

Bernardi et al. studied the impact of COVID-19 on the general surgical training program in Italy and observed a significant decline in the total number of procedures $(p=0.033)$ performed by postgraduate (PGY6) residents [2]. However, this study was underpowered with just 6 participants, and included only finalyear residents. In a more homogenous study with 192 neurosurgical residents, Zoia et al. observed a $78.6 \%$ reduction in surgical exposure across all postgraduate years [3]. A similar observation has also been made by Amparore et al. in the urology residency program [4]. It has significantly reduced both hands-on and supervised training of the surgical residents, as the emphasis has now shifted toward minimizing the operative time and the size of operative teams [4]. Aziz et al. observed that $40 \%$ of residents in the USA were not allowed in cases with a high-risk of COVID transmission, and at least $12 \%$ of residents were not allowed at all [5]. Furthermore, posting of surgical residents in COVID-19 units reduced their opportunity for rotation in surgical subspecialities, which means that

A. Rai $\cdot$ F. Huda $\cdot$ S. Basu $(\bowtie)$

All India Institute of Medical Sciences, 249203 Rishikesh, India

sombasu@hotmail.com many surgical residents may not be able to fulfil the minimum requirements of training during their residency. With a decline in operative exposure, there has been greater emphasis on simulation programs [6].

The impact of the COVID-19 pandemic on the academic front has been no less forgiving. With enforcement of social distancing, academic activities have mostly become online. While most surgical residents accept a decline in attendance in the academic programs due to irregular duty shifts, particularly in the COVID-19 emergency department and critical care units [2, 4, 7], Khalafallah et al. found an increase in both academic activities and resident attendance, which was attributed to reduced operative caseload [8]. However, the overall satisfaction with virtual learning has generally been poor [2]. Furthermore, with reduced manpower and time, and the risk of infection transmission, situated learning in ward rounds and case discussions have been pushed to a backseat [4]. Due to travel restrictions, most academic meetings and face-to-face training programs have been suspended or shifted to virtual platforms [4]. It is therefore likely that the overall quality of surgical care will be affected in the long run, as academic learning may not translate uniformly into surgical competency.

The pandemic's impact on medical research has been less uniform. Due to significant reduction of elective surgeries, residents find themselves having more time to engage in research activities [2]. However, those involved in emergency duties could not avail of this benefit [9]. With suspension of most elective surgical work and disappearing patients, quality clinical studies remain wanting in the presence of many new professional restrictions and guidelines.

Although this pandemic will have an impact on the medical education and training of the next generation of doctors, only time will tell to what extent this 
will impair professional competency. It is premature to comment on whether vaccination may improve the present training situation in the long run. While traditional forms of surgical training have been affected, it has promoted experimentation with pedagogical novelties and bench research.

\section{Funding Nil}

Conflict of interest A. Rai, F. Huda and S. Basu declare that they have no competing interests.

\section{References}

1. Huda F, Kumar P, Singh SK, Agrawal S, Basu S. Covid-19 and surgery: Challenging issues in the face of new normal-A narrative review. Ann Med Surg. 2020;60:162-7. https:// doi.org/10.1016/j.amsu.2020.10.039.

2. Bernardi L, Germani P, Del Zotto G, Scotton G, de Manzini N. Impact of COVID-19 pandemic on general surgery training program: An Italian experience. Am J Surg. 2020;220(5):1361-3. https://doi.org/10.1016/j.amjsurg. 2020.06.010.

3. Zoia C, Raffa G, Somma T, Della Pepa GM, La Rocca G, Zoli M, et al. COVID-19 and neurosurgical training and education: an Italian perspective. Acta Neurochir. 2020;162:1789-94.

4. Amparore D, Claps F, Cacciamani GE, Esperto F, Fiori C, Liguori G, et al. Impact of the COVID-19 pandemic on urology residency training in Italy. Minerva Urol Nefrol. 2020;72(4):505-9.

5. Aziz H, James T, Remulla D, et al. Effect of COVID19 on Surgical Training Across the United States: A National Survey of General Surgery Residents. J Surg Educ. 2020;S1931-7204(20):30271-3.

6. Dedeilia A, Sotiropoulos MG, Hanrahan JG, Janga D, Dedeilias P, Sideris M. Medical and Surgical Education Challenges and Innovations in the COVID-19 Era: A Systematic Review. In Vivo. 2020;34(3 Suppl):1603-11. https://doi.org/10. 21873/invivo.11950.

7. Caruana EJ, Patel A, Kendall S, Rathinam S. Impact of coronavirus 2019 (COVID-19) on training and well-being in subspecialty surgery: A national survey of cardiothoracic trainees in the United Kingdom. J Thorac Cardiovasc Surg. 2020;160(4):980-7. https://doi.org/10.1016/j.jtcvs. 2020.05.052.

8. Khalafallah AM, Jimenez AE, Lee RP, Weingart JD, Theodore N, Cohen AR, et al. Impact of COVID-19 on an academic neurosurgery department: the Johns Hopkins experience. World Neurosurg. 2020;139:877-84.

9. Fero KE, Weinberger JM, Lerman S, Bergman J. Perceived impact of urologic surgery training program modifications due to COVID-19 in the United States. Urology. 2020;143:62-7. https://doi.org/10.1016/j.urology.2020.05. 051.

Publisher's Note Springer Nature remains neutral with regard to jurisdictional claims in published maps and institutional affiliations. 